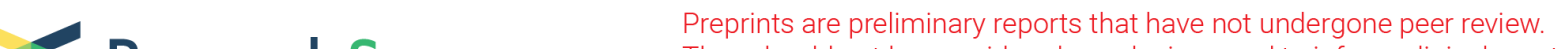 $\begin{array}{ll}\text { Research Square } & \begin{array}{l}\text { They should not be considered conclusive, used to inform clinical practice, } \\ \text { or referenced by the media as validated information. }\end{array}\end{array}$
}

\section{The R2R3-type LOMYB20s gene regulates programmed cell death and secondary wall biosynthesis, and affects anther development and dehiscence in Lily}

\section{Zheng Tong}

Institute of Tropical Bioscience and Biotechnology, Chinese Academy of Tropical Agricultural Sciences

\section{Qiuhua Li}

Department of Landscaping, Beijing Garden Expo Management Center

\section{AllahJurio Khaskheli}

Department of Ornamental Horticulture and Landscape Architecture, China Agricultural University Junping Gao

Department of Ornamental Horticulture and Landscape Architecture, China Agricultural University Junna He

Department of Ornamental Horticulture and Landscape Architecture, China Agricultural University Bo Hong ( $\square$ hongbo1203@cau.edu.cn )

Department of Ornamental Horticulture and Landscape Architecture, China Agricultural University

\section{Research article}

Keywords: Lilium, LoMYB20s, Anther dehiscence, Programmed cell death (PCD), Secondary wall biosynthesis (SWB)

Posted Date: February 21st, 2020

DOI: https://doi.org/10.21203/rs.2.15675/v2

License: (c) (i) This work is licensed under a Creative Commons Attribution 4.0 International License. Read Full License 


\section{Abstract}

Background Lilies are the widely cultivated cut flowers worldwide, while lily anthers carry a large amount of colored pollen dispersed easily to stain petals that makes serious problems for commerical sales. Improving pollen pollution in lily is one of the major goals of lily breeding.

Results In this study, we identified a putative R2R3 MYB transcription factor LoMYB20s from oriental lily ( Lilium spp. 'Siberia'). LoMYB20s mainly expressed in anther wall during the late stages of lily anther development. Suppression of LoMYB20s by virus-induced gene silencing (VIGS) in lily led to a failure of the anthers to dehisce. Induction of LoMYB20s in DEX::LoMYB20s transgenic Arabidopsis caused the rosette leaves turning yellow and the inflorescences becoming procumbent and infertile. And the downstream genes of LoMYB20s were involved in multiple metabolic processes including jasmonate (JA) biosynthetic, gibberellin (GA)-deactivating, programmed cell death (PCD), and secondary wall biosynthesis (SWB). These results suggested that LoMYB20s participated in anther development and dehiscence possibly through regulating the PCD and SWB processes in a JA/GAassociated manner.

Conclusions Our results demonstrated the indispensable role of LoMYB20s in lily anther development and dehiscence, and provide a possibility of using LoMYB20s silencing to produce anther-indehicent lilies.

\section{Background}

During the late stage of anther development, tapetal degeneration is coordinated with microspore maturation and pollen wall formation, endothecium expansion and subsequent deposition of lignocellulosic thickening, and degeneration of the septum and stomium [1, 2]. Finally, endothecium dehydration induces anther dehiscence and pollen release as the flower opens [3, 4]. Pectin-degrading polygalacturonases were found to play important roles in anther wall degeneration and anther dehiscence $[5,6]$. And programmed cell death (PCD) has also been variously contributed to the degeneration process $[7,8]$. Endothecium secondary wall thickening (SWT) is thought to provide the structure for producing the mechanical force for the anther wall to roll outward under dehydration and the degeneration facilitate the process $[4,9]$. Numerous loss-of-function mutants of SWT supported the its importance in anther dehiscence $[10,11,12,13,14]$.

Multiple types of transcriptional factors (TFs) and enzymes have been found to participate in this late stage of anther development; however, overall, the process remains largely uncharacterized $[15,16,17]$. R2R3-MYBs comprise one of the largest families of plant TFs and are important regulators playing diverse roles in anther development [18, 19]. In Arabidopsis, MYB21, MYB24, and MYB57 are critical components in the JA-mediated transcriptional cascade for stamen development and regulate overall filament elongation and anther dehiscence [20, 21]. In addition, the anther-specific gene MYB26 governs SWT in the endothecium and functions upstream of the central TF genes involved in secondary wall (SW) 
formation, including NAC SWT promoting factor1 (NST1) and NST2 [10, 11]; the GAMYB-like genes MYB33/ MYB65 facilitate tapetal and pollen development [22]; and MYB80 is required for tapetal cell death, callose dissolution, exine formation, and pollen development in Arabidopsis [23, 24] and are functionally conserved in crops such as cotton, lily, and Brassica $[25,26,27]$.

Lilies are amongst the most important and widely cultivated cut flowers worldwide; however, lily anthers carry a large amount of highly colored pollen. This easily becomes dispersed when the flower opens, leading to unsightly staining of the flowers themselves and of items that come into contact with it, such as clothing. Research into lily anther development and dehiscence will not only reveal the fundamental mechanisms involved in these processes, but will have practical implications in providing approaches for the control or prevention of pollen release in the breeding of new hybrid cultivars. In the present study, we report the functional characterization of a single R2R3-type MYB gene LOMYB20s from lily, which is specifically expressed in the late phase of anther development. Investigation of the effect of LOMYB20s silencing on lily anther development showed an inhibition on anther dehiscence, and it might be resulted from the obstruction of PCD-related anther tissue degeneration and the disturbance of natural SWB, possibly via a JA/GA (jasmonate/gibberellin) co-mediated regulatory pathway.

\section{Results}

\section{LOMYB20s in lily belongs to the R2R3-type MYB gene family}

As is well known, many MYB-family genes participate in the anther development process, in a variety of roles [20,21]. In order to obtain $M Y B$ genes with roles in anther dehiscence in lily, we designed a degenerate primer based on the highly conserved R3 DNA-binding domain of the MYB family, and finally obtained a full-length sequence of a $M Y B$ gene from mature anthers by the RACE amplification method, which was deposited in Genbank with the designation LOMYB20s and the accession number KT759161. The full-length nucleotide sequence of LoMYB20s was $807 \mathrm{bp}$, encoding a deduced protein sequence of 190 amino acids. LoMYB20s has two MYB DNA-binding domains (Fig. 1a), and is a R2R3-type MYB protein [19]. A BLAST homology search of the sequence of LoMYB20s against the NCBI protein database revealed ten similar sequences (Fig. 1a), but no study of these MYBs has so far been reported. In Arabidopsis, the R2R3-type MYB factors that are encoded by $125 \mathrm{MYB}$ genes have been categorized into 22 subgroups [19]. LoMYB20s is most closely related to MYB57, MYB21 and MYB24 from subgroup 20 of Arabidopsis, and then to MYBs from subgroup 19 (Fig. 1b).

\section{There is only one copy of LOMYB20s in the lily genome}

Southern hybridization was used to identify whether there were multiple copies or close homologs of LOMYB20s in the lily genome. The full-length sequence of LOMYB20s was used as a probe, and endonucleases $B a m H I, E c o R I, H i n d I I I$, and $X b a l$ were used for genomic DNA digestion. The results showed that two bands were visible in the EcoRI-digested product, and that only one band was visible in the other three endonuclease-digested products (Fig. 2). Given that there is a single EcoRI cleavage site in the 
LoMYB20s sequence, the results suggested that LoMYB20s is a single-copy gene, with no close homologs in the lily genome.

\section{LOMYB20s is mainly expressed in the late stages of lily anther development}

Levels of expression of LOMYB20s were examined in a range of tissues of the lily plant, including stem, leaf, petal, ovary, stigma, filament, anther, anther wall, and pollen. LOMYB20s was found to be strongly expressed in petal, stigma, filament, anther, and anther wall, but not in leaf, stem, pistil, or pollen (Fig. 3a). Expression levels of the gene were also determined at different anther developmental stages. The various stages of anther development were easily distinguishable by anther color, which progressed from white to green, then to yellow, and finally to purple [28]. A low level of expression of LoMYB20s was detected at the white and green stages, which increased at the yellow and purple stages, and then declined following anther dehiscence (Fig. 3b). These results suggested that LoMYB20s probably functioned during the late phase of anther development.

\section{LOMYB20s silencing inhibits anther development and dehiscence}

To examine the possible role of LOMYB20s in anther dehiscence, we silenced LOMYB20s in lily using virus-induced gene silencing (VIGS) [28]. Total RNA was extracted from anthers of lily plants infected with Agrobacterium tumefaciens carrying pTRV-LoMYB20s or the pTRV empty vector and analyzed by semiquantitative RT-PCR (Fig. 4a). LoMYB20s was successfully silenced in the anthers of six lines of lilies (6/100), and representative LOMYB20s-silenced flowers of lily are shown in Fig. 4b. We observed that, in the LOMYB20s-silenced lilies, the flower petals were well developed and opened normally, and the filaments and stigmas appeared to be normally elongated; however, the anthers became slender, and indehiscent (Fig. 4b). Conversely, in the control lines, the anther walls could roll outwards and the anthers were able to dehisce normally. These results indicated that silencing of LOMYB20s affected anther development, and demonstrated that LOMYB20s plays important roles in anther dehiscence.

\section{Dexamethasone (DEX) induction of LOMYB20s led to senescence and infertility in Arabidopsis}

To further investigate the function of LoMYB20s in anther development, we constructed the pTA7001GLOMYB20s vector, in which LOMYB20s is overexpressed only under DEX induction, and used this vector to transform Arabidopsis thaliana. Under the control treatment (no DEX treatment), DEX::LoMYB20s transgenic lines (LOMYB20s-expressing plants), wild-type (WT) plants, and pTA7001G transgenic plants (control plants) all grew, flowered, and produced siliques normally; the only noticeable effect was that the inflorescence stems of the LOMYB20s-expressing plants were a little short compared to those of the control plants (Additional file 1: Figure S1). Under DEX treatment, the control plants grew, flowered, and bore seed normally, whereas the LOMYB20s-expressing plants displayed serious leaf yellowing within a few days (Fig. 5a) and their inflorescences were poorly developed, or developed to be procumbent and with fewer siliques (Fig. 5b). These results indicated that overexpression of LoMYB20s caused early senescence of the transgenic plants, and severely influenced inflorescence development in Arabidopsis. 


\section{MYB homologs were induced in LoMYB20s transgenic Arabidopsis}

In an attempt to explain the phenotypes of LOMYB20s-silenced lily anthers and LoMYB20sexpressing Arabidopsis, the expression levels were detected of potentially related genes in Arabidopsis, using RT-PCR (Additional file 1: Figure S2); this revealed that several different types of genes were obviously induced.

In LoMYB20s-expressing Arabidopsis, the expression of LoMYB20s and its closest MYB homologues was initially examined (Fig. 6a, Additional file 1: Figure S2a). As anticipated, the expression of LoMYB20s was only detected following DEX treatment, and not in the controls, indicating that the phenotype of the transgenic plants sprayed with DEX was consequent upon LOMYB20s expression. Then, the expression of the closest homologues of LoMYB20s in Arabidopsis, such as MYB21, MYB24, and MYB57, was determined. This revealed that both MYB24 and MYB57 were induced, though expression of MYB21 was not detected. Next, the expression of various downstream genes of these homologous MYBs [20] was determined: the phenylalanine ammonialyase genes PAL 1 and PAL2, the terpene synthase genes TPS11 and TPS21, the alternative oxidase gene AOX1a, and the auxin-related genes SAUR63, IAA2, IAA3, IAA7, IAA19, ARF6, and ARF8. Of these, only the expression of PAL2 and TPS21 showed clear changes.

\section{Expression of PCD- and SWB-related genes was increased in LoMYB20s transgenic Arabidopsis}

Given that the rosette leaves of the transgenic Arabidopsis seedlings showed premature yellowing, RTPCR was first used to search for alterations in the expression of PCD-related genes (Additional file 1: Figure S2b). Several genes showed altered expression in the DEX-induced plants. Their expression was then precisely quantitated using qRT-PCR, which revealed dramatically higher levels of expression, relative to controls, in the LOMYB20s-expressing plants (Fig. 6b). These genes included, amongst others, three pathogen-elicited PCD-associated genes, $P R-1, P R-2$, and $P R-5$ [29], a KDEL-tailed serine protease (CysP) gene, CEP2 [23], a senescence-associated CysP gene, SAG12 [31], a vascular xylem autophagy modulator gene, MC9 [32, 33], and a senescence-associated TF gene, WRKY53 [34].

As indicated previously, in LOMYB20s-silenced VIGS lilies, the anther wall was unable to roll outwards and the anthers dehisced abnormally, which suggested that SWB might be disrupted. Accordingly, we examined the expression in transgenic Arabidopsis of a number of genes involved in SWB (Additional file 1: Figure S2c). Among these, three negative regulator genes, $M Y B 7, M Y B 32$, and $K A N T 7 / \operatorname{IRX} 11[35,36]$, and two genes encoding proteins that interact with the KANT7 gene product, $B L H 6$ and OFP4 [37], were obviously induced (Fig. 6c). In addition, two effector genes involved in xylan biosynthesis, FRA8/IRX7 [38] and IRX15L/DUF579 [39], and an endo-PG gene, QRT2 [5], were also sharply induced in LoMYB20sexpressing plants (Figure 6c).

\section{Genes of JA and GA metabolism were altered in transgenic Arabidopsis}

Among genes downstream of LOMYB20s that have been mentioned above, some have been reported to be JA- and/or GA-regulating genes, such as MYB24, 32, 57, WRKY53, SAG12, and QRT2. Therefore, the expression of genes involved in the metabolism and signaling of JA and GA was examined, including JA 
biosynthetic and metabolic genes, DAD1, LOX1-6, AOS, AOC, OPR3, ACX1, JMT, and JAR1, the JA early signal transduction genes, COI1, MYC2, MYC3, and MYC4, GA-biosynthetic genes GA200x1-5 and GA3ox 1-4, GA-deactivating genes GA2ox1-8, and DELLA genes (Additional file 1: Figure S2d). Two JA biosynthetic genes, $L O X 1$ and $J M T$ [40], and three genes of GA deactivation, GA20x4, GA2ox6, and GA20x8 [41], were induced in LOMYB20s-expressing plants compared to the control plants after DEX treatment (Fig. 6d). These results suggest that LOMYB20s could be involved in JA/GA-associated stamen developmental regulation.

\section{Discussion}

Regarding its homology to MYB proteins in Arabidopsis, LoMYB20s is most closely related to MYB21, MYB24, and MYB57 (Fig. 1b). MYB21, MYB24, and MYB57 are closely related to each other and they have been demonstrated to have a role in the JA regulation of pollen maturation, filament elongation, and anther dehiscence [21]. In contrast to the shorter filaments and petals displayed in the delayed dehiscence phenotypes exhibited by myb21, myb21myb24, or myb21myb24myb57 mutants [20, 42], only slender and indehiscent anthers were observed in LOMYB20s-silenced lily flowers (Fig. 4b). In transgenic LoMYB20s-expressing Arabidopsis plants, MYB21 expression was only slightly influenced, compared to MYB24 and MYB57, which were strongly induced (Additional file 1: Figure S2, Fig. 6a). MYB21, MYB24, and MYB57 are the key TFs in JA-regulated anther development, but the mechanism by which mutations in MYB21, MYB24, or MYB57 cause the phenotypes mentioned above has not been elucidated. Several genes have been reported to be downstreams of MYB21 or MYB24, such as PAL, AOX1a, and TPS11 and TPS21 $[42,43]$. Among these genes, only PAL2 and TPS21 were significantly induced in LoMYB20sexpressing Arabidopsis plants after DEX induction (Additional file 1: Figure S2a, Fig. 6a). A number of auxin response and JA biosynthesis genes have been shown to display obvious changes in myb21myb24 double mutants, including SAUR63, IAA2, IAA3, IAA7, IAA19, DAD1, and LOX2 [42], but none of them showed significant change in LOMYB20s-expressing plants in the present work (Additional file 1: Figure S2a). It would appear that $\angle O M Y B$ differentially affected the expression of these MYBS and their downstream genes and that, perhaps as a consequence of this, LOMYB20s regulated anther dehiscence more specifically than its homologs.

Given that LOMYB20s-expressing Arabidopsis plants exhibit a phenotype of early senescence after DEX induction (Fig. 5a), it is reasonable to suspect that $\angle O M Y B 20$ s participates in the regulation of PCD in lily anthers, where it is expressed. In the Arabidopsis MYB family, several MYBs have been reported to be associated with PCD, including MYB33, MYB65 [22], MYB80 [23], MYB101 [44], and MYB30 [45]. None of these genes showed changes in expression in LOMYB20s-expressing plants after DEX induction (Additional file 1: Figure S2b). But one of the downstream targets of $M Y B 30, P R-1$ [46] showed strongly altered expression in both LOMYB20s-expressing and control plants, compared to WT plants (Fig. 6b). Amongst other four $P R$ genes, $P R-2$ and $P R-5$ were strongly expressed only in LOMYB20s-expressing plants (Fig. 6b). $P R-1, P R-2$, and $P R-5$ are signature genes in plant defense responses to pathogenic infection [47], which also play important roles in various different abiotic stress responses [48, 49, 50, 51]. The expression of $P R$ genes is activated by the SA sensor protein NPR1, which stimulates transcriptional 
activity in response to pathogenic infection [52]. In addition, cold stimulation could also cause the induction of $P R$ genes, which is mediated by a plasma membrane-tethered NACTF, NTL6, independently of NPR1-mediated SA signaling [53]. In the present work, the expression levels of NPR1 and NTL6 were unchanged in LOMYB20s-expressing plants (Additional file 1: Figure S2b), implying that $P R-1, P R-2$, and $P R-5$ may play roles in anther development that are distinct from the known biotic and abiotic stress responses.

Furthermore, we found that the expression levels of three cell-death-related protease genes, CEP2, SAG12, and $M C 9$ were remarkably higher in LOMYB20s-expressing plants than in control plants (Additional file 1: Figure S2b, Fig. 6b). The CEP2 homolog CEP1 has been reported to be involved in the tapetal PCD process [24], and SAG12 was identified from leaves in the late stage of senescence that were visibly yellow [31]. Here, a gene upstream of $S A G 12$, the senescence-associated TF gene WRKY53 [34], was also induced in LOMYB20s-expressing plants after DEX induction (Fig. 6b). Lastly, the cysteine-type peptidase gene $M C 9$ is involved in the modulation of autophagy, to confine cell death to the appropriate target cells during Arabidopsis vascular xylem differentiation [33]. Taken together, the results suggested that LOMYB20s might have a function in the regulation of the PCD process.

Specific cells such as those comprising conducting vessels and fibers deposit a SW rich in cellulose, hemicellulose, and lignin, with lesser amounts of pectin [54]. In the anther endothecium, SW deposition is required for the generation of the tensile force necessary for stomium rupture to release pollen grains [11]. The indehiscence of lily anthers in LOMYB20s-silenced flowers (Fig. 4b), and the procumbent inflorescence stems of LOMYB20sexpressing Arabidopsis plants (Fig. 5b) suggested that either silencing or, conversely, ectopic expression of LOMYB20s might compromise SW deposition. Among many SWB regulator genes (Additional file 1: Figure S2c), the expression of $M Y B 7, M Y B 32$, and KNAT7 was dramatically induced in LOMYB20s-expressing plants (Fig. 6c). These three genes are direct targets of the secondary master switches of the SWB regulatory network, MYB46 and MYB83 [36, 55]. But neither these two MYBs nor other genes directly downstream of them, such as MYB43, MYB52, MYB54, MYB58, and $M Y B 63$, and IRX1, IRX3, IRX8, IRX9, and IRX14 were affected in LOMYB-expressing plants, suggesting that LOMYB20s probably promoted the expression of MYB7, MYB32, and KNAT7 through other unknown pathways.

MYB7 and MYB32 are negative regulators in lignin biosynthesis [56], and KNAT7 and its interacting proteins OFP4 and BLH6 are also inhibitors of SWB $[57,58]$. Although there are another two genes, FRA8 and IRX15L, involved in glucuronoxylan biosynthesis were also induced by LoMYB (Fig. 6c), they are not the main enzymes in xylan biosynthesis [56]. So based on the symptom of the decreased inflorescence stem strength (Fig. 5b) and the expression induction of the negative regulator genes in LoMYB20sexpressing plants (Fig. 6c), we are inclined to believe that LOMYB20s negatively regulated SWB in anther development. Previous studies also discovered some negative regulators of SWB which were involved in the regulation of anther dehiscence $[59,60,61]$, but how these negative regulators coordinate with positive regulators acting on anther wall development is yet to be identified and explained. 
Plant hormones interact with each other through signaling crosstalk in multiple stress responses and developmental processes. A previous study reported that GA suppressed DELLAs to promoted the expression of $D A D 1$ and $L O X 1$, up-regulated JA production, and promoted the expression of MYB21, MYB24, and MYB57 [20]. In the present work, we found that LOMYB20s could promote the expression of both JA biosynthetic and GA-deactivating genes (Fig. 6d). This result implied an antagonistic relation between JA and GA in LOMYB20s mediated regulatory network. Previous studies have observed the antagonistic interaction of JA and GA in the regulation of plant growth and defense, and the synergistic interaction of JA and GA in regulation of stamen development $[20,62]$. The findings reported here suggested some possibility of this antagonistic JA-GA interaction in LoMYB20s regulated specific PCDand SWB-related processes in anther development.

A biomechanical model describing anther opening incorporates the outer epidermal cell layer dehydration, and the endothecial layer uneven SWT in some model plant and crops [9]. In our previous work, we exhibited a reversible open and close process in mature anthers of lily controlled by the ambient humidity, and a LOPIP2-silencing induced anther indehiscent phenotype [28]. Here, we found the silencing of a LOMYB20s gene also induced lily anther indehiscent phenotype (Fig. 4), which might be related to natural PCD and SWB damage (Fig. 6). Accompanied with the development of genetic transformation system of lily $[63,64]$, these genes could be good candidates for developing anther-indehiscent lilies by molecular breeding in the future.

\section{Conclusion}

The roles of the lily flower-specific gene LOMYB20s were investigated. Silencing of LoMYB20s in cut flowers of lily led to a failure of anthers swelling and dehiscence. Overexpression of LOMYB20s in Arabidopsis promoted the expression of genes related to SWB and PCD processes and involved in JA and GA metabolism. The results suggest a possible role of LOMYB20s in the regulation of PCD and SWB processes in lily anther development and open opportunities for the development of anther-indehiscent lilies.

\section{Methods}

\section{Plant materials}

Oriental hybrid lily cultivar 'Siberia' is cultured worldwide and is one of the most popular bouquets of corm varieties on the Chinese floral market [28]. The flowers of 'Siberia' were obtained from Beijing Shengsitong Eco-Technology Co., Ltd. (China). The flower stems were placed in water immediately after harvesting and delivered instantly to the laboratory. The flower stems were then re-cut underwater to a length of $\sim 80 \mathrm{~cm}$ and placed in deionized water. Lily anther development was divided into four stages according to the distinctive colors visible at the anther surface: white, green, yellow, and purple [28].

\section{Cloning of LOMYB20s genes}


Total RNA was extracted from yellow anthers of lily using Trizol reagent (Invitrogen, USA). cDNAs for cloning the $5^{\prime}$ and $3^{\prime}$ ends of $M Y B$ were prepared from $1 \mu \mathrm{g}$ of total RNA from lily anthers, using the SMART ${ }^{\mathrm{TM}}$ RACE cDNA Amplification Kit (Clontech, USA). A degenerate primer, 5'-

KCWARRTGGGGRAAYAGGTGGTC-3', was used, together with "Universal Primer A Mix" provided in the kit, to amplify potential MYB 3' sequences in lily. Then the MYB gene-specific primer, 5'-

GGACCCTCCAAACATTCTATATCTATCT-3', was designed as a reverse primer based on the obtained 3' sequence and used with "Universal Primer A Mix" to amplify the $M Y B 5^{5}$ sequence. Finally, the complete sequence of the $M Y B$ gene was obtained using specific primers designed according to the $5^{\prime}$ and $3^{\prime}$ ends of $M Y B$. Multiple sequence alignment was carried outusing the EBI ClustalW server (http://www.ebi.ac.uk/clustalw/) and visualized using BioEdit (Ibis Biosciences, Carlsbad, USA). Phylogenetic and molecular evolutionary analysis was undertaken using MEGA version 5 [65].

\section{Southern blot analysis of LOMYB20s}

Southern blot analysis was carried out using the DIG Application Manual for Filter Hybridization (Roche, Switzerland). Genomic DNA was extracted from lily anthers using the CTAB method and digested with $B a m H I, E c o R I, H i n d I I I$, and $X b a l$. Ten $\mu$ g of each digested product was separated on an agarose gel $(0.8 \%)$ and then transferred onto a positively charged nylon membrane (Roche) by capillary transfer using 20×SSC buffer; the DNA was then UV-cross linked to the filter at a strength of $70,000 \mu \mathrm{j} \mathrm{m}{ }^{-2}$. The filter was then prehybridized and hybridized against the DIG-labeled full sequence of the $M Y B$ gene probe. The primers for the probe were: LoMYB20sFU, 5'-GGACCCTCCAAACATTCTATATCTATCT-3' and LoMYB20sFL, $5^{\prime}$-CAGCATGAAAAGCAATAAAGTTCAATTAC- $3^{\prime}$. Hybridization was performed $42^{\circ} \mathrm{C}$ and the probe was washed at $60^{\circ} \mathrm{C}$. DNA blots were visualized following film development (FUJI Photo Film, Japan) for $1 \mathrm{~h}$.

\section{Reverse transcriptase polymerase chain reaction (RT-PCR) analysis}

To determine the expression levels of the LOMYB20s gene in various different organs of lily plants, samples of leaf, stem, petal, ovary, stigma, anther, anther wall, and pollen were obtained from cut flowers (leaves and stems attached) that were about to open. In determining the expression pattern of the LOMYB20s gene in lily anthers at different developmental stages, the stages of anther development were distinguished by color [28]. To determine the expression levels of LOMYB20s and candidate related genes in transgenic Arabidopsis, the above-ground parts of Arabidopsis plants were collected on the $5^{\text {th }}$ day following DEX treatment. Total RNA from multiple organs of lily flower was extracted using a General Plant Total RNA Extraction Kit RP3301 (BioTeke, China). Total RNA from lily anthers at different developmental stages or from Arabidopsis plants was extracted using a TRIpure Total RNA Extraction Reagent RP1001 (BioTeke, China). Reverse transcription was carried out using $1 \mu \mathrm{g}$ of RNA sample and ImProm-II ${ }^{\mathrm{TM}}$ Reverse Transcriptase (Promega, USA). Semi-quantitative RT-PCR analysis was carried out using lily TIP(KJ543466), L-actin (DQ019459.1), or Arabidopsis ACTIN7 (At5g09810) as the internal control. Primer pairs used for RT-PCR detection are listed in Additional file 1: Table S1.

\section{Virus-induced gene silencing (VIGS) of LOMYB20s in lily anthers}


Silencing of LoMYB20s was performed using VIGS, with pTRV vectors (pTRV1 and pTRV2) [66]. A 426-bp fragment was amplified from the 5 ' region of $\angle O M Y B 20$ s using the primers 5 '-

gaggtaccTACCATGGACAAGAGAGTGAT-3' and 5'-ctggatcccgGCTCGCTTGGCTCGTG -3 '. The fragments were inserted into the $K p n$ and $B a m H I$ restriction sites of pTRV2 to form the pTRV2-LoMYB20s construct. pTRV2-LoMYB20s, pTRV1, and pTRV2 were transformed individually into Agrobacterium tumefaciens GV3101. For infiltration, Agrobacterium suspensions containing a 1:1 (v/v) ratio of either (i) pTRV1 and pTRV2-LoMYB20s or (ii) pTRV1 and pTRV2 (control) were prepared. Lily plants were infected when the flower buds were $\sim 4 \mathrm{~cm}$ in length and contained white anthers at an early stage of development [28]. Approximately $\sim 15$ days after infiltration, the flowers were photographed, and the anthers were collected for characterization.

\section{Arabidopsis transformation and morphological observations}

To transform the LOMYB20s gene into Arabidopsis, we first amplified the LOMYB20s ORF, using as primers: forward, 5'-aaactcgagACTCGAGATGGACAAGAGAGTGATCCCT-3'; reverse, 5'-

aaaactagtCGTCTCCATTGAAAGACTGCATAG-3'. The resultant product was ligated into the PTA7001G vector using the $X h o l$ and the Spel sites. The constructed vectors were then introduced into Agrobacterium tumefaciens strain GV3101. Transformations with Arabidopsis were performed using the flower-dip method, as described by Clough and Bent [67].

For further analysis, homozygous lines were selected on 1/2 MS medium with $25 \mathrm{mg} \mathrm{L}^{-1}$ hygromycin B (Hyg). Homozygous plant lines carrying pTA7001G or pTA7001G-MYB, along with WT plants, were placed on 1/2 MS medium for 10 days, and then transplanted to $8-\mathrm{cm}$ square pots filled with a 1:1 mixture of peat and vermiculite under greenhouse conditions $\left(23 \pm 1^{\circ} \mathrm{C}, 16 / 8 \mathrm{~h}\right.$ (day/night), and $80-100 \mathrm{lux} \mathrm{m} \mathrm{u} \mathrm{s}^{-1}$ illumination) for 15 days. Plants to be treated with DEX were sprayed daily with $30 \mu \mathrm{M}$ DEX from the $26^{\text {th }}$ day for a further 15 days, while non-treated lines were sprayed with $1 \%$ o aqueous alcohol as negative controls (DEX powder was dissolved in ethanol to give a stock solution of $30 \mathrm{mM}$; this was kept at $-20^{\circ} \mathrm{C}$ and diluted with $\mathrm{ddH}_{2} \mathrm{O}$ to give a working concentration of $30 \mu \mathrm{M}$ ). The above-ground parts of each line were sampled for gene expression examination at the $30^{\text {th }}$ day, $4 \mathrm{~h}$ after being sprayed with DEX. The morphologies of the whole plants were observed and photographed on the $30^{\text {th }}$ and $45^{\text {th }}$ days.

\section{Quantitative RT-PCR (qRT-PCR) analysis of LOMYB20s-regulated genes}

The expression of LOMYB20s-related genes was initially examined in LOMYB20s-expressing and WT Arabidopsis plants by semi-quantitative RT-PCR. Genes showing obvious changes in expression between LoMYB20s-expressing plants and control plants were selected for qRT-PCR analysis. qRT-PCR was performed using 2×Maxima SYBR Green/ROX qPCR Master Mix (Thermo Scientific, USA) and the Mx3005P QPCR System (Agilent, USA), and relative mRNA levels were calculated using the $2^{-\triangle \triangle C T}$ method [68]. Three biological replicates were performed for qRT-PCR. The ACTIN7 gene was used as a reference for normalization. All primers used for RT-PCR and qRT-PCR are listed in Additional file 1: Table S1. 


\section{Abbreviations}

DEX: dexamethasone; GA: gibberellin; JA: jasmonate; PCD: programmed cell death; PR: pathogenesisrelated; SWB: secondary wall biosynthesis; SWT: secondary wall thickening; VIGS: virus-induced gene silencing.

\section{Declarations}

\section{Acknowledgements}

Not applicable.

\section{Authors' contributions}

$\mathrm{BH}, \mathrm{JH}$, and ZT designed the study. ZT performed the majority of the experiments. QL and AJK assisted with experiments. $\mathrm{ZT}, \mathrm{JH}$, and $\mathrm{BH}$ analysed the data and wrote the paper. JG read and provide helpful discussions. All authors have read and approved the manuscript.

\section{Funding}

This study was financially supported by "National Key R\&D Program of China" (2018YFD1000400) and "National Natural Science Foundation of China" (grants numbers 31471904). The funding organizations played no role in the design of the study; collection, analysis, and interpretation of data; and in writing the manuscript.

\section{Availability of data and materials}

The data sets supporting the results of this article are included within the article and its additional file.

\section{Ethics approval and consent to participate}

Not applicable.

\section{Consent for publication}

Not applicable.

\section{Competing interests}

The authors declare that they have no competing interest.

\section{Author details}

\section{Affiliations}


Institute of Tropical Bioscience and Biotechnology, Chinese Academy of Tropical Agricultural Sciences, Xueyuan Road, Haikou, Hainan 571101, China.

Zheng Tong

Beijing Key Laboratory of Development and Quality Control of Ornamental Crops, Department of

Ornamental Horticulture and Landscape Architecture, China Agricultural University, Beijing 100193, China.

Zheng Tong, Qiuhua Li, AllahJurio Khaskheli, Junping Gao, Junna He \& Bo Hong

Department of Landscaping, Beijing Garden Expo Management Center, Beijing 100072, China

Qiuhua Li

Corresponding authors

Correspondence to Junna He or Bo Hong.

\section{References}

1. Scott RJ, Spielman M and Dickinson HG. Stamen structure and function. Plant Cell. 2004;16Suppl:S46-60.

2. Goldberg RB, Beals TP and Sanders PM. Anther development: basic principles and practical applications. Plant Cell. 1993;5:1217-29.

3. Bonner LJ and Dickinson HG. Anther dehiscence in Lycopersicon esculentum Mill. I. structural aspects. New Phytol. 1989;113:97-115.

4. Keijzer CJ. The process of anther dehiscence and pollen dispersal. New Phytol. 1987;105:487-98.

5. Ogawa M, Kay P, Wilson S and Swain SM. ARABIDOPSIS DEHISCENCE ZONE POLYGALACTURONASE1 (ADPG1), ADPG2, and QUARTET2 are polygalacturonases required for cell separation during reproductive development in Arabidopsis. Plant Cell. 2009;21:216-33.

6. Gorguet B, Schipper D, van Lammeren A, Visser RGF and van Heusden AW. ps-2, the gene responsible for functional sterility in tomato, due to non-dehiscent anthers, is the result of a mutation in a novel polygalacturonase gene. Theor Appl Genet. 2009;152:1199-209.

7. Varnier AL, Mazeyrat-Gourbeyre F, Sangwan RS and Clement C. Programmed cell death progressively models the development of anther sporophytic tissues from the tapetum and is triggered in pollen grains during maturation. J Struct Biol. 2005;152:118-28.

8. Senatore A, Trobacher CP and Greenwood JS. Ricinosomes predict programmed cell death leading to anther dehiscence in tomato. Plant Physiol. 2008;149:775-90.

9. Nelson MR, Band LR, Dyson RJ, Lessinnes T, Wells DM, Yang C, et al. A biomechanical model of anther opening reveals the roles of dehydration and secondary thickening. New Phytol. 2012;196:1030-37. 
10. Mitsuda N, Seki M, Shinozaki K and Ohme-Takagi M. The NAC transcription factors NST1 and NST2 of Arabidopsis regulate secondary wall thickenings and are required for anther dehiscence. Plant Cell. 2005;17:2993-3006.

11. Yang C, Xu Z, Song J, Conner K, Vizcay Barrena G and Wilson ZA. Arabidopsis MYB26/MALE STERILE35 regulates secondary thickening in the endothecium and is essential for anther dehiscence. Plant Cell. 2007;19:534-48.

12. Jung KW, Kim YY, Yoo KS, Ok SH, Cui MH, Jeong BC, et al. A cystathionine- $\beta$-synthase domaincontaining protein, $\mathrm{CBSX} 2$, regulates endothecial secondary cell wall thickening in anther development. Plant Cell Physiol. 2013;54:195-208.

13. Huang C, Zhang R, Gui J, Zhong Y and Li L. The receptor-like kinase AtVRLK1 regulates secondary cell wall thickening. Plant Physiol. 2018;177:671-83.

14. Zhao SQ, Li WC, Zhang Y, Tidy AC and Wilson ZA. Knockdown of Arabidopsis ROOT UVB SENSITIVE4 disrupts anther dehiscence by suppressing secondary thickening in the endothecium. Plant Cell Physiol. 2019;60:2293-306.

15. Mandaokar A, Thines B, Shin B, Lange BM, Choi G, Koo YJ, et al. Transcriptional regulators of stamen development in Arabidopsis identified by transcriptional profiling. Plant J. 2006;46:984-1008.

16. Wilson ZA, Song J, Taylor B and Yang C. The final split: the regulation of anther dehiscence. J Exp Bot. 2011;62:1633-49.

17. Acosta IF and Przybyl M. Jasmonate signaling during Arabidopsis stamen maturation. Plant Cell Physiol. 2019;60:2648-659.

18. Dubos C, Stracke R, Grotewold E, Weisshaar B, Martin C and Lepiniec L. MYB transcription factors in Arabidopsis. Trends Plant Sci. 2010;15:573-81.

19. Stracke R, Werber M and Weisshaar B. The R2R3-MYB gene family in Arabidopsis thaliana. Curr Opin Plant Biol. 2001;4:447-56.

20. Cheng H, Song S, Xiao L, Soo HM, Cheng Z, Xie D, et al. Gibberellin acts through jasmonate to control the expression of MYB21, MYB24, and MYB57to promote stamen filament growth in Arabidopsis. PLoS Genet. 2009;5:e1000440.

21. Mandaokar A and Browse J. MYB108 acts together with MYB24 to regulate jasmonate-mediated stamen maturation in Arabidopsis. Plant Physiol. 2009;149:851-62.

22. Millar AA and Gubler F. The Arabidopsis GAMYB-like genes, MYB33 and MYB65, are microRNAregulated genes that redundantly facilitate anther development. Plant Cell. 2005;17:705-21.

23. Phan HA, lacuone S, Li SF and Parish RW. The MYB80 transcription factor is required for pollen development and the regulation of tapetal programmed cell death in Arabidopsis thaliana. Plant Cell. 2011;23:2209-24.

24. Zhang ZB, Zhu J, Gao JF, Wang C, Li H, Li H, et al. Transcription factor AtMYB103 is required for anther development by regulating tapetum development, callose dissolution and exine formation in Arabidopsis. Plant J. 2007;52:528-38. 
25. Phan HA, Li SF and Parish RW. MYB80, a regulator of tapetal and pollen development, is functionally conserved in crops. Plant Mol Biol. 2012;78:171-83.

26. Sui J, He J, Wu J, Gong B, Cao X, Seng S, et al. Characterization and functional analysis of transcription factor LoMYB80 related to anther development in Lily (Lilium Oriental Hybrids). J Plant Growth Regul. 2015;34:545-57.

27. Xu Y, lacuone S, Li SF and Parish RW. MYB80 homologues in Arabidopsis, cotton and Brassica: regulation and functional conservation in tapetal and pollen development. BMC Plant Biol. 2014;14:278.

28. Tong Z, Li Q, Yang Y, Dai F, Gao J and Hong B. Isolation and expression analysis of LoPIP2, a lily (Lilium Oriental Hybrids) aquaporin gene involved in desiccation-induced anther dehiscence. Sci Hortic. 2013;164:316-22.

29. Stone JM, Heard JE, Asai T and Ausubel FM. Simulation of fungal-mediated cell death by fumonisin B1 and selection of fumonisin B1-resistant (fbr) Arabidopsis mutants. Plant Cell. 2000;12:1811-22.

30. Hierl G, Howing T, Isono E, Lottspeich F and Gietl C. Ex vivo processing for maturation of Arabidopsis KDEL-tailed cysteine endopeptidase 2 (AtCEP2) pro-enzyme and its storage in endoplasmic reticulum derived organelles. Plant Mol Biol. 2014;84:605-20.

31. Weaver LM, Gan S, Quirino B and Amasino RM. A comparison of the expression patterns of several senescence-associated genes in response to stress and hormone treatment. Plant Mol Biol. 1998;37:455-69.

32. Bollhoner B, Zhang B, Stael S, Denance N, Overmyer K, Goffner D, et al. Post mortem function of AtMC9 in xylem vessel elements. New Phytol. 2013;200:498-510.

33. Escamez S, Andre D, Zhang B, Bollhoner B, Pesquet E and Tuominen H. METACASPASE9 modulates autophagy to confine cell death to the target cells during Arabidopsis vascular xylem differentiation. Biol Open. 2016;5:122-9.

34. Miao Y, Laun T, Zimmermann P and Zentgraf U. Targets of the WRKY53 transcription factor and its role during leaf senescence in Arabidopsis. Plant Mol Biol. 2004;55:853-67.

35. Hay A and Tsiantis M. KNOX genes: versatile regulators of plant development and diversity. Development. 2010;137:3153-65.

36. Ko JH, Jeon HW, Kim WC, Kim JY and Han KH. The MYB46/MYB83-mediated transcriptional regulatory programme is a gatekeeper of secondary wall biosynthesis. Ann Bot. 2014;114:1099-107.

37. Liu Y and Douglas CJ. A role for OVATE FAMILY PROTEIN1 (OFP1) and OFP4 in a BLH6-KNAT7 multiprotein complex regulating secondary cell wall formation in Arabidopsis thaliana. Plant Signal Behav. 2015;10:e1033126.

38. Lee C, Teng Q, Huang W, Zhong R and Ye ZH. The F8H glycosyltransferase is a functional paralog of FRA8 involved in glucuronoxylan biosynthesis in Arabidopsis. Plant Cell Physiol. 2009;50:812-27.

39. Brown D, Wightman R, Zhang Z, Gomez LD, Atanassov I, Bukowski JP, et al. Arabidopsis genes IRREGULAR XYLEM (IRX15) and IRX15L encode DUF579-containing proteins that are essential for normal xylan deposition in the secondary cell wall. Plant J. 2011;66:401-13. 
40. Wasternack C. Jasmonates: an update on biosynthesis, signal transduction and action in plant stress response, growth and development. Ann Bot. 2007;100:681-97.

41. Yamaguchi S. Gibberellin metabolism and its regulation. Annu Rev Plant Biol. 2008;59:225-51.

42. Reeves $\mathrm{PH}$, Ellis $\mathrm{CM}$, Ploense $\mathrm{SE}$, Wu MF, Yadav V, Tholl D, et al. A regulatory network for coordinated flower maturation. PLoS Genet. 2012;8:e1002506.

43. Li Y, Jiang J, Du ML, Li L, Wang XL and Li XB. A cotton gene encoding MYB-like transcription factor is specifically expressed in pollen and is involved in regulation of late anther/pollen development. Plant Cell Physiol. 2013;54:893-906.

44. Alonso-Peral MM, Li J, Li Y, Allen RS, Schnippenkoetter W, Ohms S, et al. The microRNA159-regulated GAMYB-like genes inhibit growth and promote programmed cell death in Arabidopsis. Plant Physiol. 2010;154:757-71.

45. Raffaele S, Rivas S and Roby D. An essential role for salicylic acid in AtMYB30-mediated control of the hypersensitive cell death program in Arabidopsis. FEBS Lett. 2006;580:3498-504.

46. Vailleau F, Daniel X, Tronchet M, Montillet JL, Triantaphylides C and Roby D. A R2R3-MYB gene, AtMYB30, acts as a positive regulator of the hypersensitive cell death program in plants in response to pathogen attack. Proc Natl Acad Sci U S A. 2002;99:10179-84.

47. Van Loon LC, Rep M and Pieterse CM. Significance of inducible defense-related proteins in infected plants. Annu Rev Phytopathol. 2006;44:135-62.

48. Hon WC, Griffith M, Mlynarz A, Kwok YC and Yang DS. Antifreeze proteins in winter rye are similar to pathogenesis-related proteins. Plant Physiol. 1995;109:879-89.

49. Liu WX, Zhang FC, Zhang WZ, Song LF, Wu WH and Chen YF. Arabidopsis Di19 functions as a transcription factor and modulates $P R 1, P R 2$, and $P R 5$ expression in response to drought stress. Mol Plant. 2013;6:1487-502.

50. Seo PJ, Lee AK, Xiang F and Park CM. Molecular and functional profiling of Arabidopsis pathogenesis-related genes: insights into their roles in salt response of seed germination. Plant Cell Physiol. 2008;49:334-44.

51. Zeier J, Pink B, Mueller MJ and Berger S. Light conditions influence specific defence responses in incompatible plant-pathogen interactions: uncoupling systemic resistance from salicylic acid and PR-1 accumulation. Planta. 2004;219:673-83.

52. Wu Y, Zhang D, Chu JY, Boyle P, Wang Y, Brindle ID, et al. The Arabidopsis NPR1 protein is a receptor for the plant defense hormone salicylic acid. Cell Rep. 2012;1:639-47.

53. Seo PJ, Kim MJ, Park JY, Kim SY, Jeon J, Lee YH, et al. Cold activation of a plasma membranetethered NAC transcription factor induces a pathogen resistance response in Arabidopsis. Plant J. 2010;61:661-71.

54. Hao Z and Mohnen D. A review of xylan and lignin biosynthesis: foundation for studying Arabidopsis irregular xylem mutants with pleiotropic phenotypes. Crit Rev Biochem Mol Biol. 2014;49:212-41. 
55. Ko JH, Kim WC and Han KH. Ectopic expression of MYB46 identifies transcriptional regulatory genes involved in secondary wall biosynthesis in Arabidopsis. Plant J. 2009;60:649-65.

56. Zhong RQ and Ye ZH. Secondary cell walls: biosynthesis, patterned deposition and transcriptional regulation. Plant Cell Physiol. 2015;56:195-214.

57. Li E, Wang S, Liu Y, Chen JG and Douglas CJ. OVATE FAMILY PROTEIN4 (OFP4) interaction with KNAT7 regulates secondary cell wall formation in Arabidopsis thaliana. Plant J. 2011;67:328-41.

58. Liu Y, You S, Taylor-Teeples M, Li WL, Schuetz M, Brady SM, et al. BEL1-LIKE HOMEODOMAIN6 and KNOTTED ARABIDOPSIS THALIANA7 interact and regulate secondary cell wall formation via repression of REVOLUTA. Plant Cell. 2014;26:4843-61.

59. Kim YY, Jung KW, Jeung JU and Shin JS. A novel F-box protein represses endothecial secondary wall thickening for anther dehiscence in Arabidopsis thaliana. J Plant Physiol. 2012;169:212-6.

60. Wang H, Mao Y, Yang J and He Y. TCP24 modulates secondary cell wall thickening and anther endothecium development. Front Plant Sci. 2015;24:436.

61. Nguyen HTK, Hyoung S, Kim HJ, Cho KM and Shin JS. The transcription factor YMYB2 acts as a negative regulator of secondary cell wall thickening in anther and stem. Gene. 2019;702:158-65.

62. Song S, Qi T, Wasternack $C$ and Xie D. Jasmonate signaling and crosstalk with gibberellin and ethylene. Curr Opin Plant Biol. 2014;21:112-9.

63. Wei C, Cui Q, Lin Y and Jia GX. Efficient Agrobacterium tumefaciens (Smith \& Towns.) Connmediated transformation of Lilium 'Sorbonne' with genes encoding anthocyanin regulators. Can $\mathrm{J}$ Plant Sci. 2017;97:796-807.

64. Yan R, Wang ZP, Ren YM, Li HY, Liu N and Sun HM. Establishment of efficient genetic transformation systems and application of CRISPR/Cas9 genome editing technology in Lilium pumilum DC. Fisch. and Lilium longiflorum White Heaven. Int J Mol Sci. 2019;20:2920.

65. Tamura K, Peterson D, Peterson N, Stecher G, Nei M and Kumar S. MEGA5: molecular evolutionary genetics analysis using maximum likelihood, evolutionary distance, and maximum parsimony methods. Mol Biol Evol. 2011;28:2731-39.

66. Ratcliff F, Martin-Hernandez AM and Baulcombe DC. Technical Advance. Tobacco rattle virus as a vector for analysis of gene function by silencing. Plant J. 2001;25:237-45.

67. Clough SJ and Bent AF. Floral dip: a simplified method for Agrobacterium-mediated transformation of Arabidopsis thaliana. Plant J. 1998;16:735-43.

68. Livak KJ and Schmittgen TD. Analysis of relative gene expression data using real-time quantitative PCR and the $2^{-\triangle \Delta C T}$ method. Methods. 2001;25:402-8.

\section{Additional File Information}

Additional file 1: Figure S1. Growth phenotypes of transgenic Arabidopsis lines of DEX::LOMYB20s plants. Figure S2. The semi-quantitative PCR detection of related genes. Table S1. Primer sequences used in this study. 
Figures

A

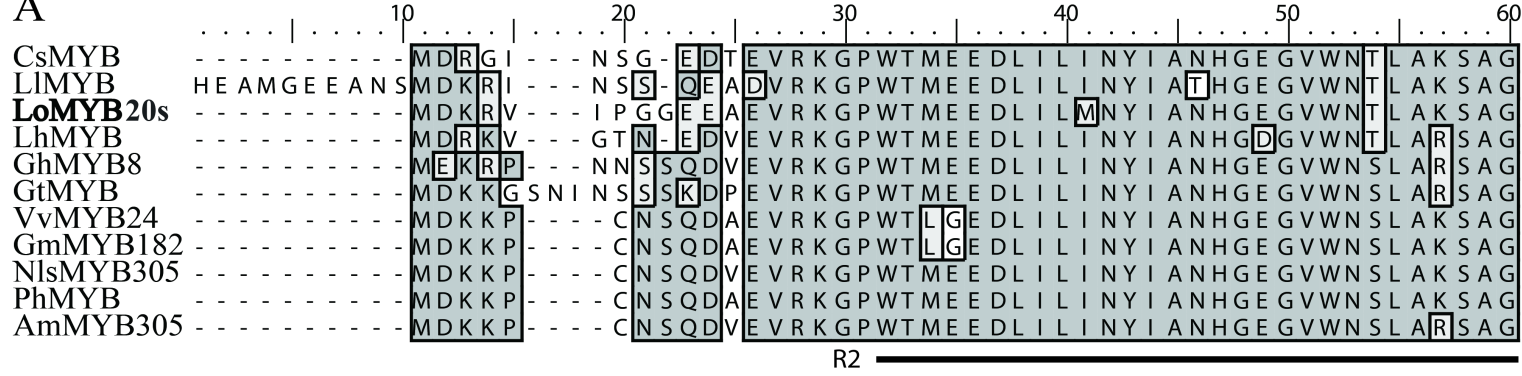

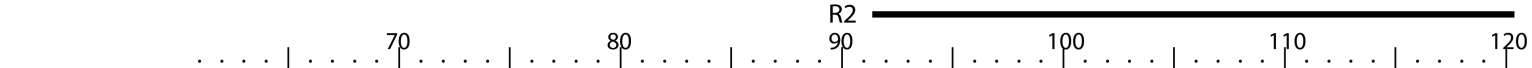

CSMYB LKRTGKSCRLRWLNYLRPDVRRGNI TPEEQLL I MELHSRWGNRWSK I ARR QLPRTDNE I K LIMYB L KRTGKSCRLRWLNYLRPDVRRGNITPEEOLLI MELHSRWGNRWSK I AROLPGRTDNE IK

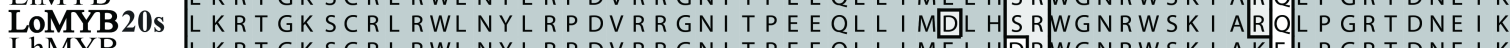
LhMYB $\quad$ LKRTGKSCRLRWLNYLRPDVRRGNI TPEEQLL I MEL HDRWGNRWSK I AKELLGRTDNE I K GhMYB8 L KRTGK SCRLRWLNYLRPDVRRGNI TPEEQLLIMELHAKWGNRWSKIAKHLPGRTDNEIK GTMYB $\quad$ LKRTGKSCRLRWLNYLRPDVRRGNITPEEOLLIMELHAKWGNRWSKIAKHLPGRTDNEIK VVMYB24 LKRTGK SCRLRWLNYLRPDVRRGN I TDEE QDL I MELHAKWGNRWSKI AKHLPGRTDNE IK GmMYB182 L KRTGK SCRLRWL NYLRPDVRRGN I T DE EQ L I MEL HAKWGNRWSK I AKHLPGRTDNE IK NlsMYB305 L KRTGK SCRLRWLNYLRPDVRRGN I TPEE QLL I MELHAKWGNRWSK I AKHLPGRTDNE IK PhMYB LKRTGK SCRLRWLNYLRPDVRRGNITPEEOLLIMELHAKWGNRWSK I AKHLPGRTDNE IK AmMYB305LKRTGK SCRLRWLNYLRPDVRRGNI TPEEQLL I MELHAKWGNRWSK I AKTLL PRTDNE I K

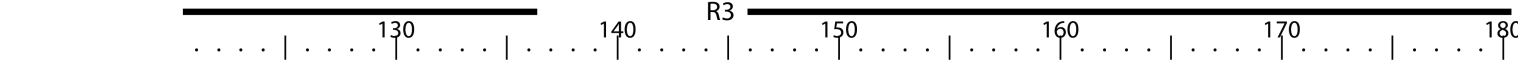

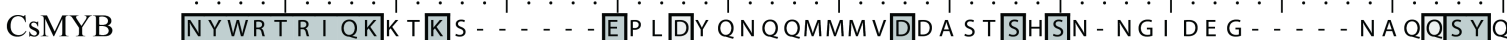

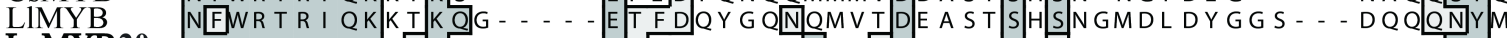

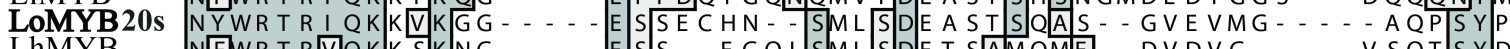

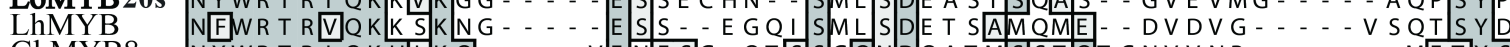

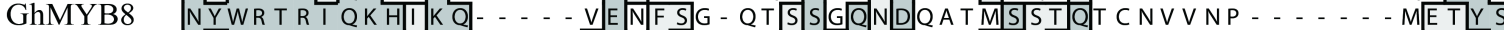

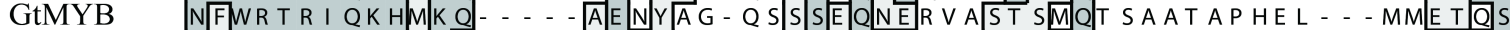

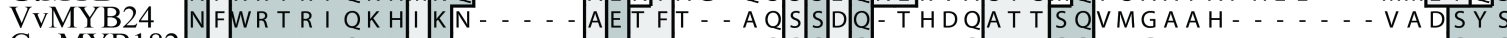

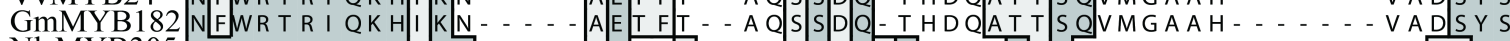

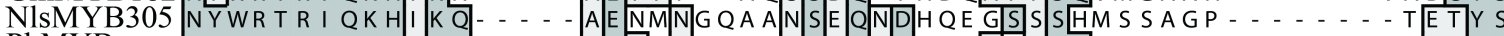

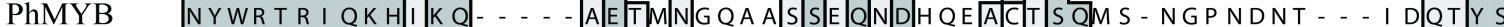

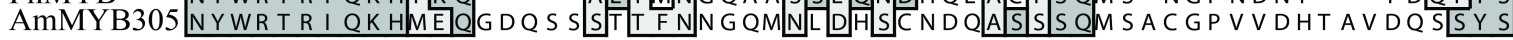

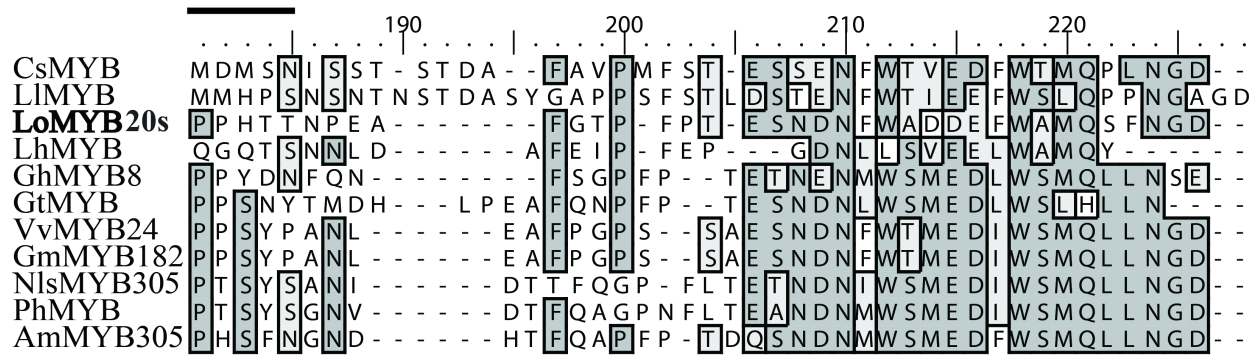

$\mathrm{B}$

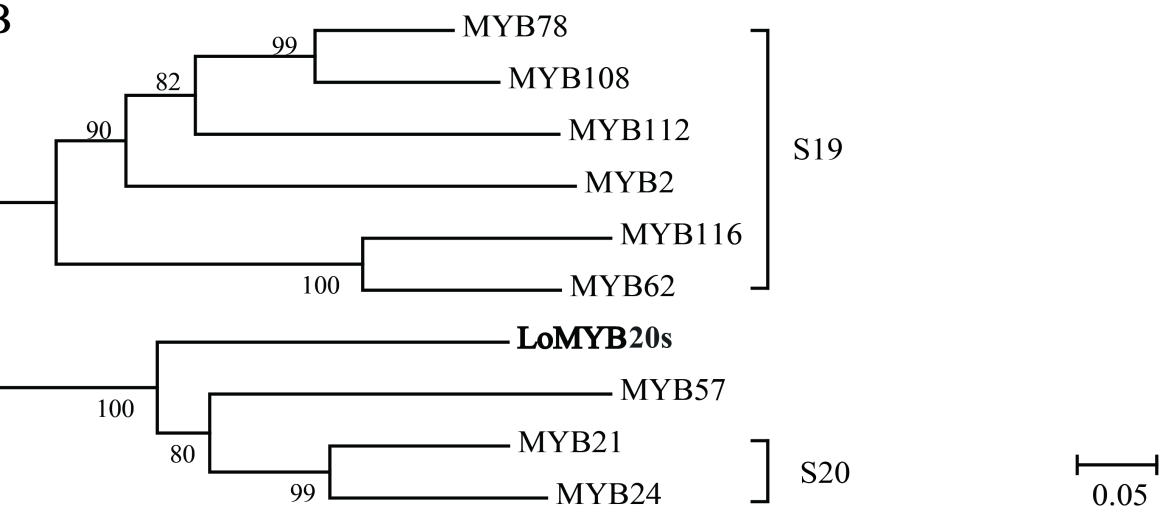

Figure 1

Comparison of the deduced amino acid sequence of LoMYB20s with those of MYBs from other species. a Amino acid alignment of LoMYB20s and its most closely related MYBs from other plant species.

Identical and similar amino acids are colored dark gray and light gray, respectively. Black lines under the 
sequences indicate the R2 and R3 domains of the MYB family, respectively. b Phylogenetic relationship between LoMYB20s and its most closely related MYB subgroup members in Arabidopsis. Branch lengths are proportional to accumulated amino acid substitutions. Bootstrap values indicate the divergence of each branch.

$23130 \mathrm{bp}$

$9416 \mathrm{bp}$

$6557 \mathrm{bp}$

$4361 \mathrm{bp}$

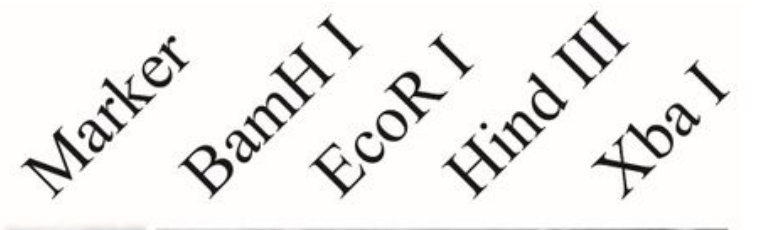

$2322 \mathrm{bp}$

$2000 \mathrm{bp}$

$1000 \mathrm{bp}$

750 bp

$500 \mathrm{bp}$

$250 \mathrm{bp}$

$100 \mathrm{bp}$

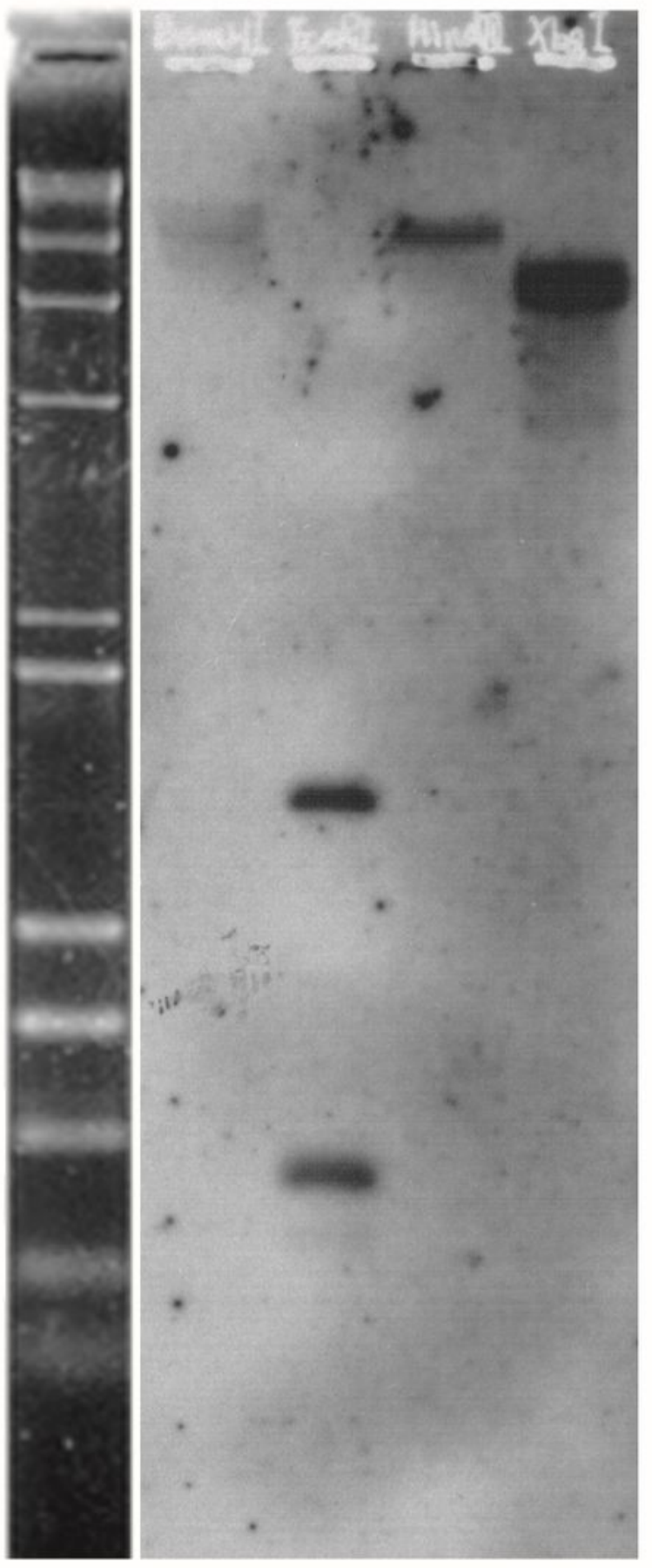

\section{Figure 2}


Southern blot of LoMYB20s in lily genome. Endonucleases BamHI, EcoRI, HindIII, and Xbal were used for genomic DNA digestion. $10 \mu \mathrm{g}$ of each digested product was separated by electrophoresis and then transferred onto a positively charged nylon membrane. The membrane was hybridized with a DIG-labeled LoMYB20s probe.

A

\section{LoMYB20s}

$T I P$

B

\section{LoMYB20s}
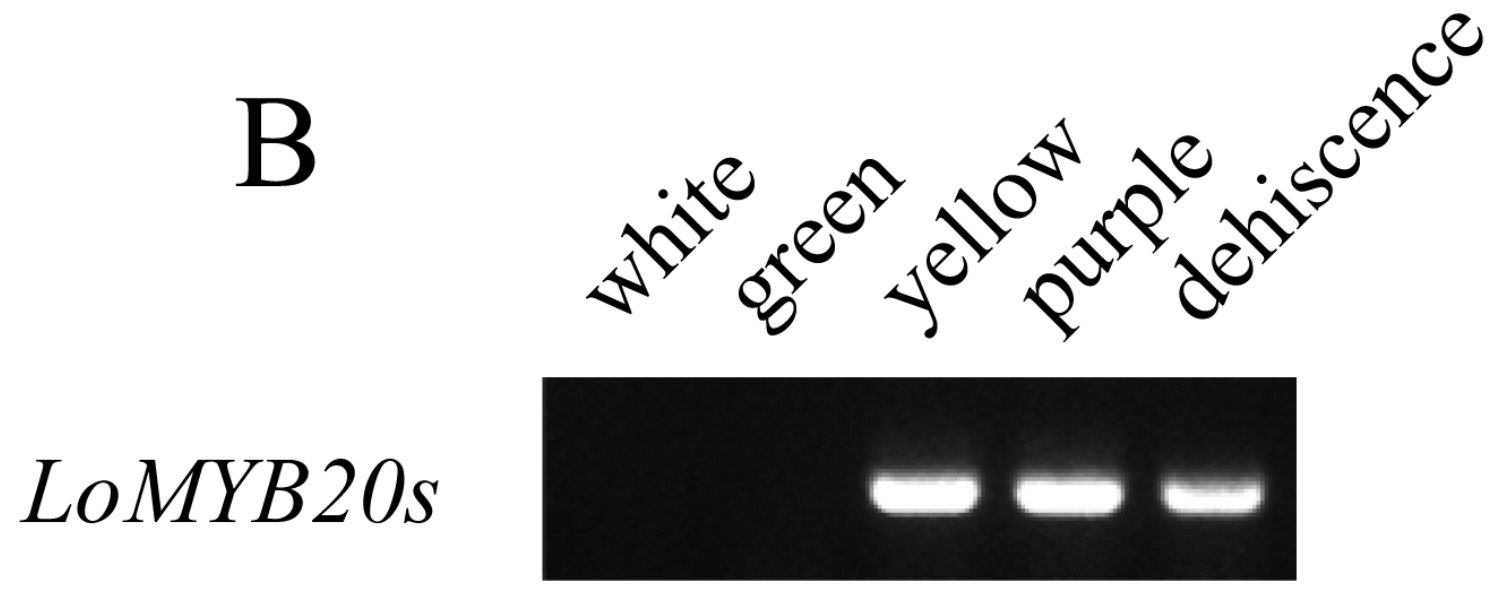
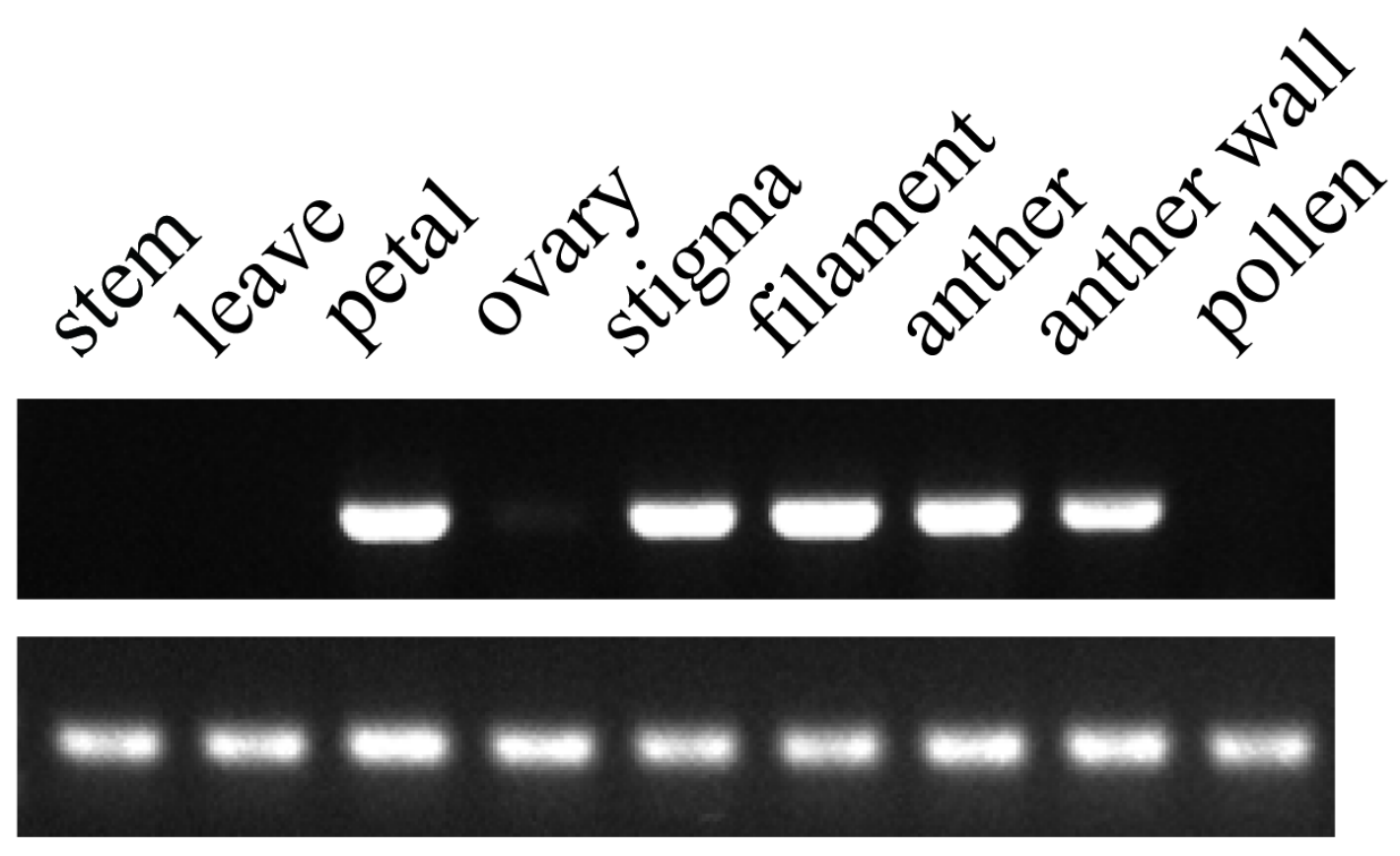

TIP

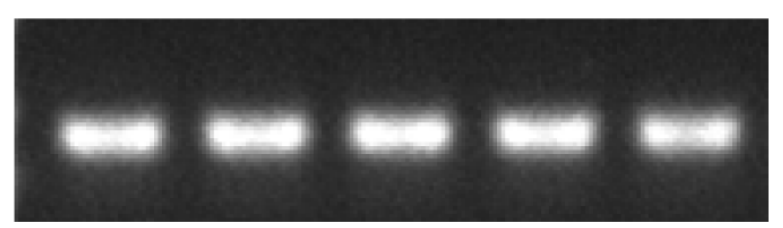

Figure 3

Expression analysis of LoMYB20s transcripts. a Expression levels of LoMYB20s in different organs of lily cut flower. b Expression levels of LoMYB20s at different stages of anther development. The stages of anther development were distinguished by anther color, which ranged from white (early developmental stage), through green (middle developmental stage), to yellow (late developmental stage), and finally to purple (fully mature stage), followed by dehiscence. 


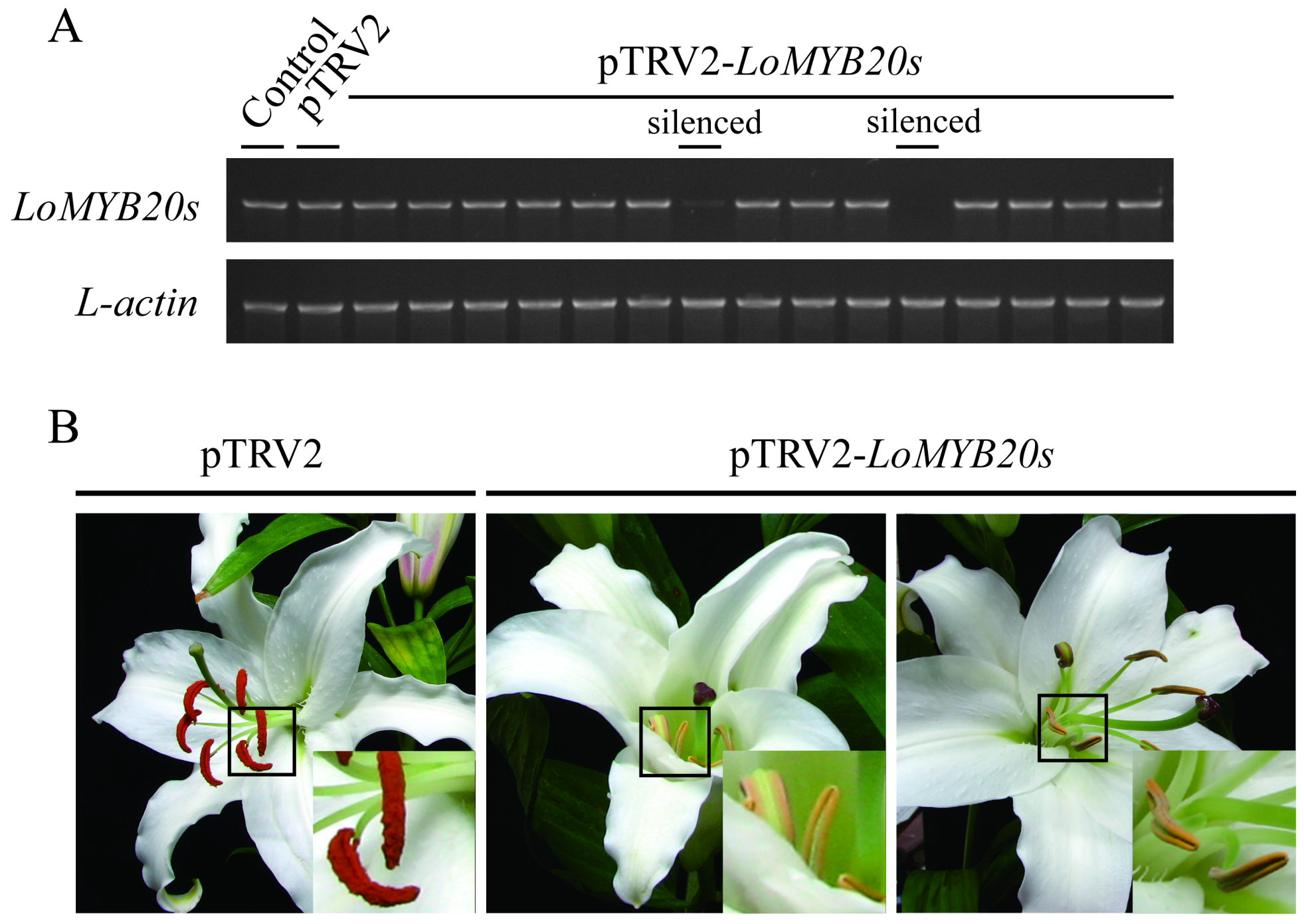

Figure 4

Silencing of LoMYB20s in lily anthers by VIGS. a RT-PCR analysis of LoMYB20s in lily anthers infected with Agrobacterium tumefaciens carrying PTRV2-LoMYB20s. Control, anthers from non-infiltrated flowers; pTRV2, anthers from flowers infiltrated with Agrobacterium containing the TRV empty vector (pTRV1 + pTRV2); pTRV2-LoMYB20s, anthers from flowers infiltrated with Agrobacterium containing TRVLoMYB20s (pTRV1 + pTRV2-LoMYB). b Morphologies of flowers and anthers in which the expression of LoMYB20s had been silenced. The photographs were taken 15 days after infiltration. The picture in the lower right corner of each photograph is a 2.5-times amplification of the region indicated by the black box. 

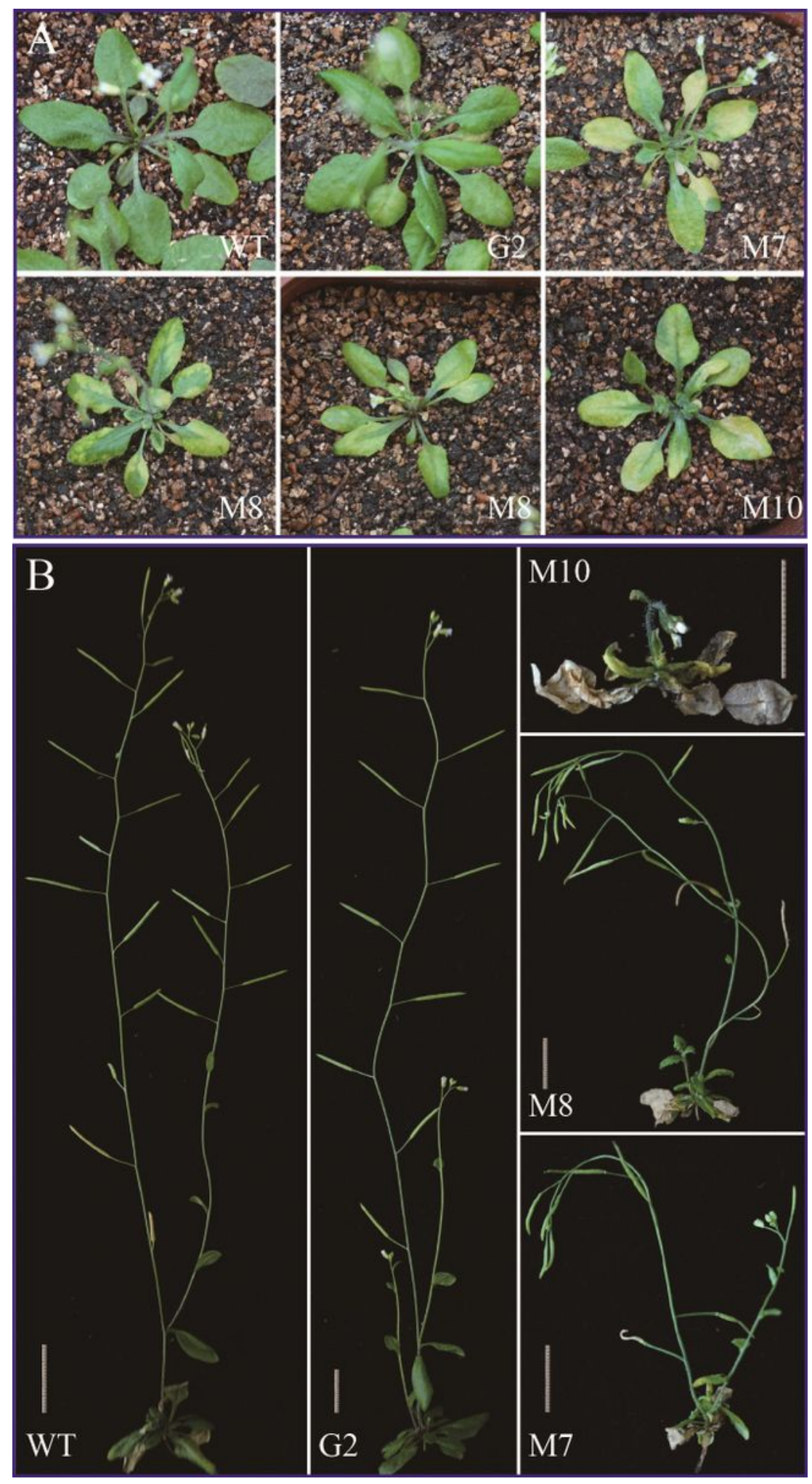

Figure 5

The altered phenotypes of transgenic Arabidopsis DEX::LoMYB20s plant lines. The plants of WT (wildtype), G2 (empty vector), and M7, M8, and M10 lines (DEX::LoMYB20s) were sprayed with $30 \mu \mathrm{M}$ DEX (+DEX) or ddH2O (-DEX with 1\%o aqueous alcohol) once per day. a The prematurely senescent leaves of the DEX::LoMYB20s lines. The pictures were taken $5 \mathrm{~d}$ after the first DEX treatment. $\mathrm{b}$ The inhibited 
development of the inflorescence stems of the DEX::LoMYB20s lines. The pictures were taken $20 \mathrm{~d}$ after the first DEX treatment. The bar in each picture represents $2 \mathrm{~cm}$.

A

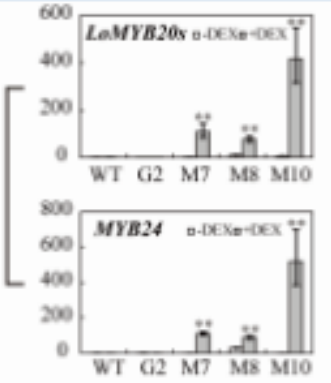

B
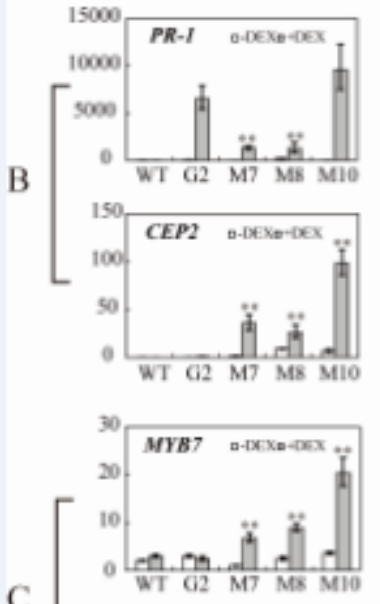

C
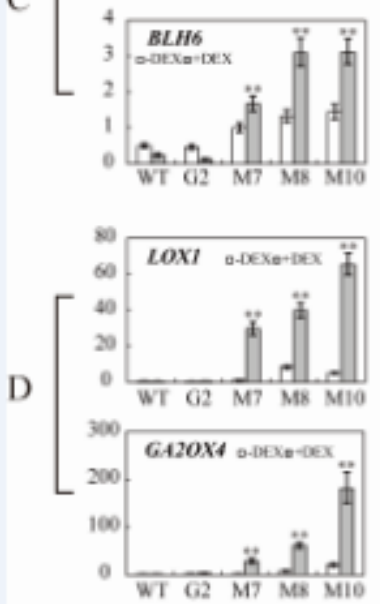
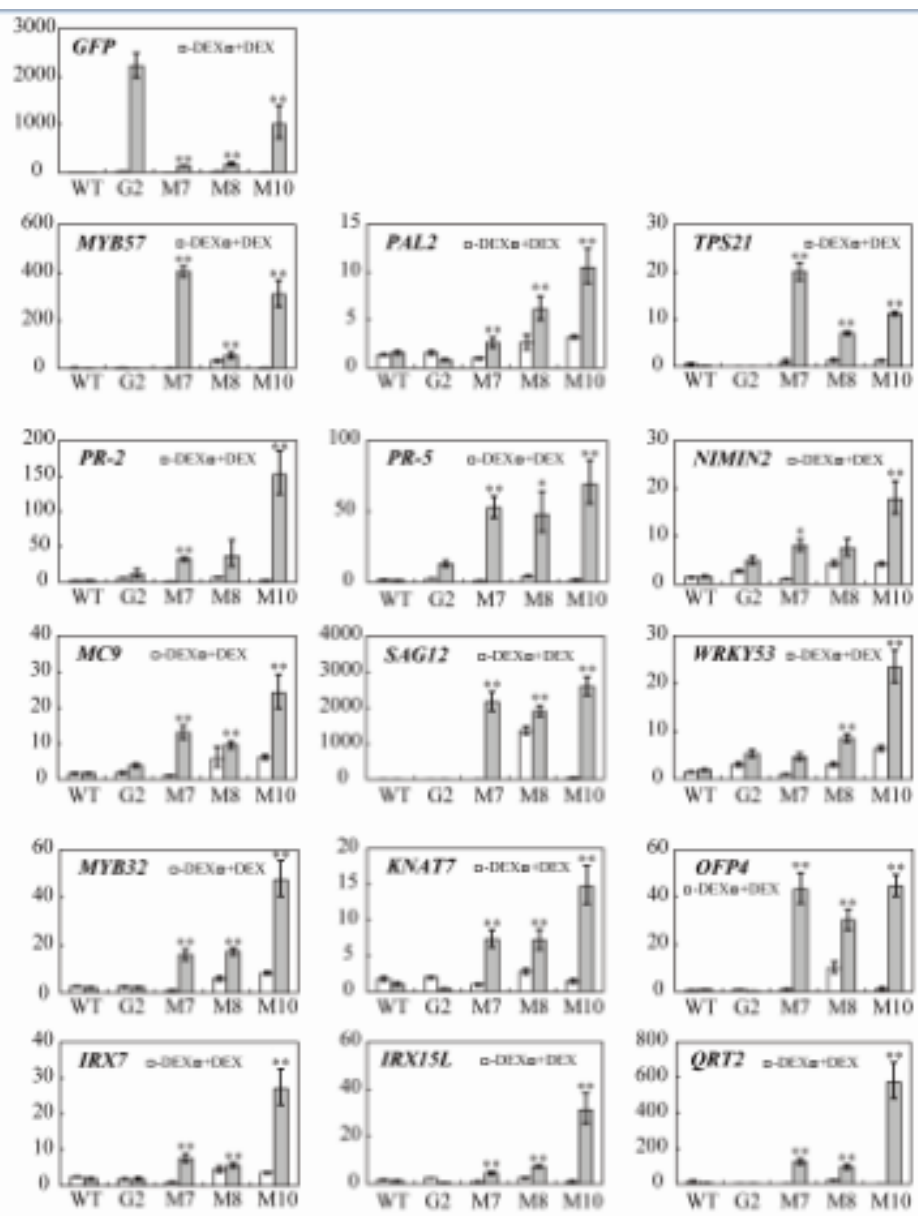
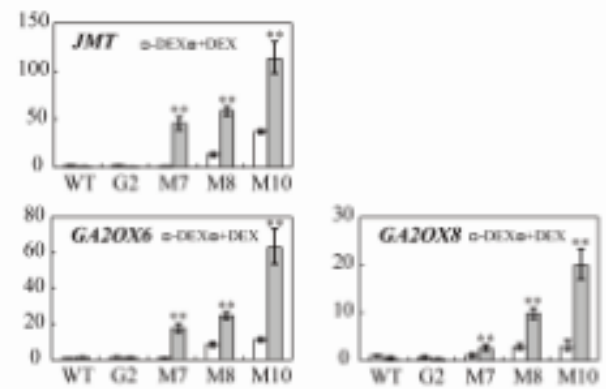

Figure 6

qRT-PCR analysis of the expression of LoMYB20s-regulated genes. WT: wild-type; G2: pTA7001G empty vector transgenic line; M7, M8, and M10: DEX::LoMYB20s transgenic lines. Plants were sprayed with 30 $\mu \mathrm{M}$ DEX (+DEX) or ddH2O (-DEX with 1\%o aqueous alcohol) once per day, and the samples were collected $4 \mathrm{~h}$ after DEX treatment on the fifth day. Asterisk above an error bar indicates a significant difference (Student's t-test, $n=3$ ) compared with the $\mathrm{G} 2+$ DEX plants. * indicates a difference of $\mathrm{P}<0.05$, and ** indicates a difference of $P<0.01$. a LoMYB20s and its Arabidopsis homologs and downstream genes; $b$ plant PCD-related genes; c SWB regulator and effector genes; $d \mathrm{JA}$ and GA biosynthesis and signal genes.

\section{Supplementary Files}


This is a list of supplementary files associated with this preprint. Click to download.

- Additionalfile1n.pdf 